\title{
AS ESTRATÉGIAS E A ESTRUTURA DA INDÚSTRIA DE MASSAS ALIMENTICIAS DO RIO GRANDE DO SUL (2001 - 2007) ${ }^{1}$
}

\author{
STRATEGY AND STRUCTURE OF THE PASTA INDUSTRY AT RIO GRANDE DO \\ SUL STATE $(2001-2007)$
}

\author{
Pascoal José Marion Filho ${ }^{2}$ \\ Vitor Francisco Dalla Corte ${ }^{3}$
}

RESUMO: A pesquisa identifica as estratégias e avalia a estrutura da indústria de massas alimentícias do Rio Grande do Sul no período de 2001 a 2007. Utiliza-se como base teórica na análise o modelo estrutura-conduta-desempenho (ECD) e as estratégias competitivas de Porter (1980) e de Mintzberg (1988). Os resultados mostram que a concentração da indústria cai de 2001 para 2006 e que existem barreiras à entrada importantes para os ingressantes no setor, como a capacidade ociosa das empresas instaladas, o valor do capital inicial e o acesso aos canais de comercialização. Em relação às estratégias competitivas de Porter, a diferenciação é a que mais se destaca. Entre as tipologias de Mintzberg, a qualidade do produto é considerada pelas empresas como sendo o grande diferencial competitivo. O desempenho da indústria também está piorando, mesmo com o aumento na produção, uma vez que a lucratividade está em queda e as empresas estão perdendo participação no mercado.

PALAVRAS-CHAVE: Estratégias; Massas Alimentícias; Concentração Industrial; Barreiras à Entrada.

ABSTRACT: This research identifies the strategies and evaluates the structure of the pasta industry the State of Rio Grande do Sul in the period between 2001 and 2007. The theoretical base used in the analysis was the structure-conduct-performance (SCP) model and the competitive strategies by Porter (1980) and Mintzberg (1988). The results demonstrate that industrial concentration declines from 2001 to 2006 and, that it exists barriers to entry that are important to the ones who ingress in the sector like the idle capacity of the already installed companies, the value of the initial capital needed and the access to market channels. In relation to Porter's competitive strategies, differentiation is the most emphasized. Among Mitzemberg's typologies, the product quality is considered by the industry as the major competitive differential. The industry performance is also getting worst because even with an increase in production the profitability is dropping and the companies are losing market share.

KEY WORDS: Strategies; Pasta; Industrial Concentration; Barriers to Entry.

\footnotetext{
${ }^{1}$ Artigo Recebido em 10.03.2010. Revisado por pares em 12.09.2011. Recomendado em 12.09.2011 por Leomar dos Santos Editor. Publicado em 26.01.2012.

Organização Responsável pelo periódico: Universidade regional de Blumenau - FURB - www.furb.br/rn
}

\footnotetext{
${ }^{2}$ Universidade Federal de Santa Maria - UFSM - pascoaljmarion@yahoo.com.br

${ }^{3}$ Universidade Federal de Santa Maria - UFSM - vitordallacorte@gmail.com
} 


\section{INTRODUÇÃO}

Atualmente, as massas alimentícias (ou macarrão) estão entre os alimentos mais conhecidos em todo o planeta, sendo o Brasil um dos grandes produtores e consumidores em nível mundial. Segundo dados da Associação Brasileira das Indústrias de Massa Alimentícias - ABIMA (2007), a produção brasileira de macarrão (em toneladas) no ano de 1994 que foi de 780 mil, passou a ser de 850 mil em 1995, 860 mil em 1996, 920 mil em 1997 e em 2007 chegou a 1.220 mil. Com esta sequência de crescimento, o Brasil passou a ocupar em 2007 a terceira posição em termos de produção mundial de massas alimentícias, atrás somente da Itália e dos Estados Unidos.

A indústria nacional de massas alimentícias, bem como todos os participantes da cadeia produtiva, sofreu e ainda sofre com a desregulamentação do setor e a queda de barreiras tarifárias e não-tarifárias para a importação de trigo, farinha de trigo e massas alimentícias.

Segundo a Associação Brasileira das Indústrias de Trigo - ABITRIGO (2007), em 1988 o país tinha se aproximado da auto-suficiência na produção do trigo, importando 11,3\% das necessidades de consumo do cereal, e depois da desregulamentação passou a importar, em média (1990 - 2006), 65,24\% do consumo brasileiro.

As mudanças que ocorreram no mercado afetaram a disponibilidade interna da principal matéria-prima para os produtores de massas alimentícias, a farinha de trigo, e as medidas liberalizantes adotadas pelo governo, como a abertura do mercado e o fim dos subsídios, vem exigindo das empresas uma constante busca por meios de se manterem competitivas num ambiente em permanente mutação. Estas alterações geram pressões por mudanças na organização e na forma como as empresas atuam, uma vez que as regras do jogo são alteradas, o que justifica uma pesquisa com o objetivo de identificar as estratégias e avaliar a estrutura da indústria de massas alimentícias do Rio Grande do Sul no período de 2001 a 2007.

A opção por restringir o estudo ao estado do Rio Grande do Sul se deve a importância que o mesmo possui na produção nacional de trigo ( $2^{\circ}$ maior produtor $)$ e ao seu pioneirismo e representatividade na produção de massas alimentícias ( $3^{\circ}$ maior produtor).

$\mathrm{O}$ artigo está organizado em cinco seções, sendo esta introdução a primeira delas. A segunda seção traz os referenciais teóricos do estudo, o modelo ECD e as estratégias competitivas de Porter e de Mintzberg. Na seqüência, faz-se referência à metodologia e a fonte de dados, e, na quarta seção, analisam-se as estratégias e a organização da indústria de massas alimentícias do Rio Grande do Sul. Por fim, na quinta seção, apresentam-se as conclusões da pesquisa.

\section{REFERENCIAL TEÓRICO}

Para estudar as estratégias e a organização da indústria de massas alimentícias do Rio Grande do Sul, utilizam-se como referenciais teóricos o modelo ECD (estrutura - conduta desempenho) e as estratégias competitivas de Porter (1980) e de Mintzberg (1988). A seguir, descrevem-se cada um dos referenciais e apresentam-se as fundamentações para as escolhas.

Revista de Negócios, ISSN 1980-4431, Blumenau, v16, n.3, p.96 - 112, Julho/Setembro 2011. 


\subsection{O modelo estrutura-conduta-desempenho (ECD)}

O modelo estrutura-conduta-desempenho (ECD) é oriundo da Organização Industrial (OI) e, segundo Farina (1997), serve para determinar as forças responsáveis pela organização da indústria e como estas têm se alterado no tempo. O modelo visava inicialmente avaliar a relação entre a concentração na indústria e a lucratividade dos oligopólios, objetivando auxiliar na política antitruste dos EUA. Admitia-se que quanto mais concentrado o mercado, maior a possibilidade de ocorrer uma coalizão tácita entre as empresas para maximização conjunta dos lucros, o que resultaria em uma prática semelhante à de um monopólio, trazendo, desta forma, prejuízos para a sociedade.

O relacionamento da estrutura de mercado com o desempenho no modelo, passando pela conduta das empresas e assumindo um sentido de causalidade da primeira para a última, deriva dos modelos de concorrência perfeita e monopólio. De acordo com a teoria econômica neoclássica, a empresa monopolista maximizadora de lucros produz menos e pratica preços mais elevados do que a empresa que atua no mercado de concorrência perfeita, o que é ruim para a sociedade.

Com o passar do tempo, o modelo ECD passou por várias formalizações e, segundo Marion Filho (1997), apesar das versões mais tradicionais considerarem o sentido de casualidade como unidirecional, ou seja, seguindo da estrutura para o desempenho, sendo a primeira determinada exogenamente, as versões mais atualizadas abandonaram este sentido de casualidade, admitindo que a estrutura possa ser determinada endogenamente. Esta visão é compartilhada por Rosa (2001), que se utiliza da citação de Porter (1980) para reforçar a idéia. Segundo o autor, vários modelos têm explorado aspectos da empresa em um caráter dinâmico, considerando que todo o sistema evolui constantemente em função de mudanças internas e externas a ele, o que permite que tais modelos forneçam respostas mais completas e favoráveis em relação aos objetivos pretendidos.

Sobre esta afirmação, Scherer e Ross (1990) afirmam que existem importantes efeitos de feed-back entre as variáveis do modelo. Como exemplo cita que grandes esforços de pesquisa e desenvolvimento (variável da conduta) realizados por uma firma podem alterar a tecnologia predominante na indústria, a estrutura de custos e o grau de diferenciação física do produto. Outro exemplo citado, é que políticas de determinação de preços podem encorajar a entrada de novas firmas no mercado ou expulsar firmas mais fracas, conseqüentemente alterando a estrutura de mercado.

Contudo, adota-se neste artigo o modelo adaptado de Carlton e Perloff (1990) e, a seguir, apresentam-se os seus componentes.

\subsubsection{A estrutura de mercado}

Para Resende e Boff (2002), a estrutura de mercado desempenha um importante papel dentro do modelo ECD. Entretanto, Leite (1998) destaca que o termo tem três sentidos diferentes. O primeiro refere-se às características mais aparentes do mercado, que é definido conforme o número de empresas concorrentes entre si e pela oferta de produtos diferenciados ou homogêneos; o segundo ponto de vista diz respeito ao modelo estrutura-condutadesempenho, onde as características das firmas estão relacionadas a varáveis como 
concentração, barreiras à entrada, bens substitutos, dentre outras. Já a terceira maneira de se enfocar estrutura é semelhante ao segundo ponto de vista, contudo, acrescendo-se aspectos que dão um sentido de dinâmica.

Leite (1998) menciona que a estrutura engloba características de organização do mercado e que a mesma influencia estrategicamente a natureza da competição e os preços dentro deste. De acordo com Carlton e Perloff (1990), a estrutura de mercado pode ser definida analisando as seguintes variáveis: número de vendedores/ compradores (concentração), barreiras à entrada, integração vertical, diferenciação do produto e diversificação da produção.

A concentração é um indicador sintético da concorrência existente em um mercado. Para Kon (1994), a medida dá os elementos empíricos necessários para essa avaliação e serve também para comparações intertemporais, o que permite examinar a dinâmica do mercado do lado da oferta.

Farina (1993) lembra que o conceito de concentração não se refere apenas ao número de participantes de um dado mercado; mais do que isto, se refere ao controle de uma grande proporção de uma determinada atividade econômica por uma pequena proporção dos participantes nesta atividade. Sobre a sua quantificação, Kon (1994) afirma que normalmente são utilizados indicadores que seguem três critérios, que são: a capacidade produtiva, o número de empregados e os ativos possuídos. A capacidade produtiva pode estar relacionada à quantidade física de produção ou a valores monetários (valor das vendas, valor adicionado etc.). O número de empregados é normalmente utilizado para mensurar o poder das empresas pela maior facilidade de obter informações. Contudo, esta medida é influenciada pelas técnicas empregadas, pelo grau de integração e pelo nível de automatização das diferentes firmas.

As medidas mais utilizadas para quantificar a concentração em uma indústria, segundo Kon (1994), são a razão de concentração (Cr) e o índice Herfindahl-Hirschman (HH). A Razão de concentração $(\mathrm{Cr})$ mede a proporção da indústria de posse das $k$ maiores empresas, tomando-se como base o indicador escolhido. Seu cálculo é dado por:

$$
\mathbf{C r}(k)=\sum_{i=1}^{k} \mathbf{P i}
$$

Sendo:

$k=$ número das maiores empresas que fazem parte do cálculo; e,

$\mathrm{Pi}=$ participação percentual da i-ésima empresa no mercado.

Esta medida é de fácil interpretação e indica à participação no mercado (concentração) das $k$ maiores empresas que formam a indústria, sendo o máximo 100\% (monopólio).

O Índice de Herfindahl-Hirschman (HH) é definido pela soma dos quadrados da participação percentual de cada empresa em relação ao tamanho total da indústria. Este índice leva em conta todas as empresas da indústria e é calculado pela fórmula apresentada a seguir:

Revista de Negócios, ISSN 1980-4431, Blumenau, v16, n.3, p.96 - 112, Julho/Setembro 2011. 


$$
\mathbf{H H}=\sum_{i=1}^{n} \mathbf{P i}^{\mathbf{2}}
$$

Sendo:

$n$ : número de empresas da indústria participantes no mercado; e,

Pi: participação percentual da i-ésima empresa no mercado.

Este índice assume o valor máximo de 10.000 (se o Pi estiver em \%), quando existe apenas uma empresa na indústria (monopólio). O índice assume seu menor valor $(10.000 / \mathrm{n})$ quando as empresas têm participação igualitária no mercado. $\mathrm{O}$ valor de $\mathrm{HH}$ aumenta conforme aumenta a desigualdade entre as empresas pertencentes à indústria, apresentando-se, desta forma, como um bom indicador da situação de mercado. Convém salientar que o tamanho da empresa é levado em conta pela sua participação ( $\mathrm{Pi}$ ) ao quadrado, ou seja, as empresas menores contribuem menos que proporcionalmente para o valor do índice. Desta forma, quanto maior o índice, mais concentrado é o mercado e, conseqüentemente, menor a concorrência entre as empresas.

Segundo Usdoj (1997), o mercado não é concentrado quando o valor do índice $\mathrm{HH}$ estiver abaixo de 1.000; tem concentração moderada quando se situar no intervalo entre 1.000 e 1.800; e é altamente concentrado quando atingir valor superior a 1.800 .

As demais variáveis da estrutura, como barreiras à entrada, integração vertical, diversificação da produção e diferenciação do produto, também são avaliadas para se conhecer a organização da indústria e a sua dinâmica.

As barreiras à entrada, variável da estrutura, são importantes determinantes da conduta e do desempenho da indústria, já que a sua presença, no longo prazo, oportuniza a prática de preços acima do nível competitivo (CARLTON e PERLOFF, 1990). Elas também servem de base para a reação de firmas já estabelecidas frente à entrada de novos concorrentes, uma vez que indicam a extensão na qual elas podem elevar seus preços de venda sem induzir a entrada de novos concorrentes na indústria (BEM, 1991).

Segundo Marion Filho (1997), as barreiras à entrada citadas com maior freqüência na literatura econômica são: economias de escala, necessidades de capital, acesso aos canais de distribuição, desvantagens de custos independentes de escala, produto diferenciado e política pública (regulação). Servem como exemplo de barreiras à entrada: o valor do investimento inicial; os acessos à tecnologia e à matéria-prima; a escala mínima de produção para entrar na indústria; a qualificação da mão-de-obra; a ociosidade das empresas instaladas; a dificuldade de colocar o produto no mercado e outras barreiras existentes aqui não especificadas.

A integração vertical pode ser caracterizada como a expansão da indústria além de seu mercado de atuação, podendo esta ser para trás (da indústria para seus fornecedores de matérias-primas e demais insumos) ou para frente (da indústria para os distribuidores). Esta é uma forma de se reduzir custos, assim como proporcionar aos produtores um maior controle sobre o seu ambiente econômico, visto que firmas integradas podem estabelecer uma estrutura de preços verticais, restringindo as margens de lucro dos seus competidores menos integrados (BEM, 1991). 
Cabe ainda ressaltar a diversificação da produção e a diferenciação do produto como variáveis estruturais. Segundo Kon (1994), entende-se por diversificação a introdução de um produto em um mercado no qual a firma ainda não participa, ou seja, a busca do investimento em uma nova indústria, modificando sua linha de produção. Já a diferenciação do produto pode ser entendida como a introdução de uma nova mercadoria na gama de produtos de uma empresa para um mercado em específico, que tenha a característica de ser substituta próxima de outra anteriormente por ela produzida.

\subsubsection{A conduta das empresas}

O segundo conceito do modelo ECD a ser apresentado é o da conduta. Segundo Bem (1991), ele pode ser expresso como sendo o comportamento que as firmas apresentam no mercado em relação a preços, produção, características do produto, pesquisa e desenvolvimento $(\mathrm{P} \& \mathrm{D})$ e propaganda. Além disso, ele é responsável por estabelecer um elo entre a estrutura e o desempenho.

Assim, a conduta consiste nas políticas da empresa em relação ao mercado concorrencial em que a empresa se encontra, seja esta uma política efetiva ou potencial. É avaliando a conduta da empresa que serão demonstradas as políticas de fixação de preços e produção, bem como a fixação de padrões de qualidade e políticas de ação ou coação da empresa (BEM,1991).

Para Leite (1998), a variável conduta é representada pelas estratégias competitivas adotadas pelas empresas quando se relaciona o modelo ECD à competitividade. A conduta de mercado diz respeito aos processos de decisão e as relações intra-industriais, bem como aos padrões de comportamento que as firmas assumem para se ajustar ou se adequar ao mercado no qual elas operam.

Existem amplas variações de condutas das empresas. No entanto, a maioria dos trabalhos empíricos realizados tem como objetivo determinar a extensão em que os padrões de concorrência ou o comportamento estão associados à estrutura de mercado (determinante da conduta) e ao desempenho de mercado (determinado pela conduta).

No modelo teórico adotado neste trabalho, considera-se como conduta os gastos com pesquisa e desenvolvimento (P\&D), a realização de contratos entre empresas e, de uma forma complementar, as estratégias genéricas de Porter (1980) e Mintzberg (1988), descritas a seguir.

\subsubsection{As estratégias competitivas de Porter}

Os primeiros ensaios acadêmicos sobre estratégia foram produzidos por docentes e discentes da Harvard Business School. Entre os vários estudos acadêmicos desenvolvidos por essa escola, destacam-se os da área de organização industrial (OI), a exemplo do modelo ECD (estrutura, conduta e desempenho) já citado acima.

Porter (1980) define as estratégias competitivas como ações ofensivas ou defensivas para criar uma posição defensável em uma indústria e assim enfrentar as forças competitivas. Genericamente, segundo Porter (1986), pode-se utilizar como formas de competição no mercado a liderança em custo (obter uma vantagem sustentável em termos de custo sobre os demais competidores e utilizá-la como forma de vender produtos a um preço mais baixo), a 
diferenciação (atender a preferências dos consumidores que não possam ser satisfeitas por um bem padronizado) e o enfoque (ou nicho de mercado, em que os clientes possuem preferências ou exigências únicas).

Porter (1986) também afirma que a empresa que aplica apenas uma das estratégias genéricas apresenta melhor desempenho. As empresas que procuram adotar uma estratégia híbrida ou que fracassam na busca por uma das estratégias foram por ele designadas como stuck-in-the-middle (expressão traduzida para o português como meio-termo). O fato de uma empresa ser classificada como "meio-termo" não significa que ela não emprega métodos e armas competitivas típicas de uma ou mais das estratégias genéricas, mas apenas que a sua estratégia como um todo carece de consistência interna (DESS e DAVIS, 1984 apud SILVA, CARNEIRO e CAVALCANTI, 2003).

Vários estudos sobre estratégia empresarial foram desenvolvidos utilizando as tipologias de Porter (1980), como comprova a revisão de literatura de Miller e Dess (1993), realizada em artigos publicados no Journal of Management Studies entre 1986 e 1990. Segundo os autores, o trabalho de Porter - Estratégia Competitiva - foi citado, aproximadamente, na metade dos artigos publicados, demonstrando a proliferação e aceitação das idéias do autor.

\subsubsection{Estratégias competitivas de Mintzberg}

Mintzberg (1988) entende que a maioria das estratégias explicitadas na literatura são falhas, pois focam de forma muito estreita alguns tipos especiais ou propoem agregações arbitrárias. Por isso, o autor propôs novas tipologias de estratégias genéricas a partir do conceito de diferenciação, com detalhamento maior do que o apresentado nas estratégias de Porter (1980).

Segundo Silva, Carneiro e Cavalcanti (2003), pode-se definir as estratégias genéricas de Mintzberg (1988) como sendo:

- Diferenciação por qualidade - a estratégia se caracteriza pela oferta de um produto melhor do que o dos concorrentes, embora não fundamentalmente diferente (maior confiabilidade, maior durabilidade ou desempenho superior);

- Diferenciação por design (projeto) - ocorre quando se oferece um produto diferente do apresentado pela concorrência. A diferença básica desta estratégia para aquela de diferenciação por qualidade é que a diferenciação por design busca efetivamente oferecer algo diferente e não simplesmente ou necessariamente melhor;

- Diferenciação por suporte - existe quando é oferecido algo mais junto com o produto. Em geral, a ampliação do nível de serviços agregados (prazo de entrega menor, financiamento à venda, assistência técnica etc.) ou a oferta de produtos complementares;

- Diferenciação por imagem - ela se caracteriza pelo desenvolvimento da imagem do produto, tornando-o distinto dos demais. Esta imagem pode ser criada através da propaganda, como também através de técnicas de promoção, apresentação, ou pela inclusão de detalhes que deixam o produto mais atrativo;

- Diferenciação por preço - a estratégia é cobrar um preço mais baixo pelo produto. Se os demais atributos do bem forem iguais ou não muito diferentes dos de seus concorrentes, 
os consumidores tenderão a preferir aquele que exibir um preço mais baixo. Mintzberg insiste em afirmar que diferenciação por preço não é o mesmo que a minimização de custo de Porter. Isto porque a minimização de custo só se caracteriza como vantagem competitiva caso se traduza em menor preço no mercado (caso fosse visível para o consumidor);

- Não-diferenciação - essa estratégia se baseia no fato de que é possível copiar as ações de outras empresas, desde que o mercado ofereça espaço para produtos concorrentes e a empresa se especialize em acompanhar e imitar os lançamentos dos concorrentes, apoiando seus próprios lançamentos com ações inovadoras e eficientes de marketing. A estratégia de não-diferenciação assemelha-se ao conceito de meio-termo desenvolvido por Porter (1980). Entretanto, duas diferenças merecem destaque em relação ao modelo de Porter:

i) Mintzberg considera que a estratégia pode ser desenvolvida explicitamente, enquanto Porter considera o meio-termo como um tipo residual, resultante da implementação inadequada ou ineficiente de uma das estratégias genéricas puras; e,

ii) ao contrário do que Porter supõe para o meio-termo, Mintzberg não condena a estratégia a um desempenho inferior ao das demais estratégias.

Kotha e Vadlamani (1995), em um estudo das empresas de manufatura nos Estados Unidos, concluíram que as tipologias de Mintzberg (1988) têm maior clareza e poder descritivo que as tipologias de Porter (1980). Os autores citam as seguintes possíveis explicações para justificar os resultados: (i) mudanças no ambiente competitivo devido ao incremento da competição global (especialmente no setor de manufatura) e (ii) mudanças decorrentes da utilização de novas tecnologias (por exemplo, just in time). A maior complexidade do novo ambiente competitivo exigiria maior refinamento das tipologias de estratégias genéricas.

Entretanto, estudo realizado por Silva e Melo (1998) no setor de seguros brasileiro confirma o poder descritivo das tipologias de Porter e afirma que as mesmas possuem um poder explanatório superior as apresentadas por Minztberg (1988).

Fugindo um pouco da polêmica sobre a superioridade explicativa de uma sobre a outra tipologia, Hill (1988) ressalta que pesquisadores da área de Administração Estratégica sugerem a utilização conjunta de estratégias, mesmo ocorrendo superposições em uma mesma empresa. Ainda, o autor comenta que a adoção de ambas não leva, necessariamente, a um desempenho inferior.

Neste estudo, utilizam-se as teorias do modelo ECD, de Porter (1980) e de Mintzberg (1988) como complementares, buscando identificar os diferentes posicionamentos das empresas produtoras de farinha de trigo, mesmo que elas não adotem um posicionamento único em relação às estratégias competitivas. A seguir descreve-se o desempenho, último componente do modelo ECD.

\subsection{O Desempenho das empresas}

Os resultados obtidos pelas empresas da indústria determinam o desempenho. Segundo Scherer e Ross (1990), o mesmo é conseqüência da conduta ou do comportamento da empresa. Refere-se aos resultados finais atingidos pelas empresas em função da estrutura e 
da conduta no mercado onde atuam. Com isso, na análise do desempenho industrial, deve-se sempre observar os resultados obtidos (ex-post facto). Para os autores, os trabalhos empíricos concentram-se nos resultados financeiros, sendo a lucratividade uma das variáveis mais utilizadas.

A lucratividade é muitas vezes relacionada ao grau de concentração. Contudo, esta afirmação pode ser difícil de ser comprovada, porque muitas vezes o lucro pode ser resultado de outras fontes, tais como mudanças inesperadas na relação entre a demanda e os custos. Apesar disso, quando os lucros excessivos são mantidos por um longo período de tempo, são persistentes, só podem ser explicados pela existência do poder de mercado.

De acordo com Scherer e Ross (1990), o bom desempenho é multidimensional e engloba os seguintes elementos, não necessariamente nesta ordem de importância:

a) as decisões sobre o que, quanto e como produzir, que devem ser eficientes em dois aspectos: os recursos escassos, que não devem ser desperdiçados, e as decisões de produção, que devem corresponder qualitativa e quantitativamente à demanda dos consumidores;

b) as operações dos produtores devem ser progressivas, tirando vantagem das oportunidades abertas pela ciência para aumentar o output por unidade de input e fornecer aos consumidores novos produtos superiores;

c) as operações dos produtores devem facilitar o emprego total de recursos, em especial os recursos humanos;

d) a distribuição de renda deve ser eqüitativa, o que implica que a remuneração dos produtores não seja excessiva.

Segundo Bem (1991), a evolução dos preços também é uma variável importante do desempenho da indústria, uma vez que a amplitude na mudança reflete as margens de lucro das empresas.

Vê-se que diversas variáveis podem ser utilizadas para avaliar o desempenho. No entanto, utilizam-se neste trabalho as variáveis preço, quantidade e lucratividade, destacadas na seção da metodologia e coleta de dados.

\section{METODOLOGIA E COLETA DE DADOS}

Utiliza-se na análise das estratégias e da organização da indústria de massas alimentícias do Rio Grande do Sul o método descritivo. Segundo Gil (1996), as pesquisas descritivas têm como objetivo primordial à descrição das características de determinada população ou fenômeno ou, então, o estabelecimento de relações entre variáveis.

No presente trabalho o intuito é apresentar as modificações do ambiente setorial segundo teorias distintas, mas complementares entre si. Para tanto, utiliza-se o modelo ECD e as estratégias de Porter (1980) e de Mintzberg (1988).

A estrutura da indústria é avaliada a partir da concentração industrial, das barreiras à entrada, da diferenciação do produto e da diversificação da produção. A conduta (estratégias) é analisada a partir de acordos e/ou contratos entre os agentes da cadeia de produção e das estratégias competitivas de Porter e de Mintzberg (ver referencial teórico). O desempenho da indústria é determinado pelo comportamento dos preços médios dos produtos, da evolução da quantidade produzida e pela lucratividade das empresas. 
Os dados utilizados na análise são primários e secundários. Os dados primários foram coletados através da aplicação de um questionário estruturado nas empresas produtoras de massas alimentícias do Rio Grande do Sul. Este questionário assemelha-se aos já aplicados por Zaeyen (1986), Moraes (1996) e Marion Filho (1997). Antes do envio, fez-se um pré-teste em duas empresas e alguns ajustes em relação aos termos técnicos utilizados. Em seguida, teve-se o contato telefônico e o envio dos questionários para os gestores das empresas que faziam parte do cadastro industrial da FIERGS no ano de 2007 (42 empresas). De uma forma complementar a esta relação, foi efetuado um comparativo com as empresas filiadas a ABIMA, respectiva associação brasileira destas empresas. Constatou-se que todas as empresas associadas do Rio Grande do Sul na ABIMA (06 empresas) constavam no cadastro industrial da FIERGS, fato este que explica a utilização do cadastro da FIERGS (2007) como referência, pois engloba um número maior de empresas.

Apesar dos esforços realizados para obter informações das 42 empresas produtoras de massas alimentícias do Rio Grande do Sul, retornaram 14 questionários (33,33\%). No entanto, as empresas respondentes são representativas, pois, juntas utilizavam mais de $67 \%$ do total de empregados efetivos e faturavam mais de $70 \%$ do total da indústria no ano de 2007 . Apesar da importância destas empresas na indústria, a amostra analisada não é probabilística.

Os dados secundários foram utilizados para o cálculo do índice de concentração $\mathrm{HH}$ (variável da estrutura da indústria) em relação ao total de empregados envolvidos na indústria. Estes dados foram obtidos junto ao Cadastro Industrial da Federação das Indústrias do Rio Grande do Sul (FIERGS) para os anos de 2001 e 2006.

\section{AS ESTRATÉGIAS E A ORGANIZAÇÃO DA INDÚSTRIA}

Para análise das estratégias e da organização da indústria de massas alimentícias do Rio Grande do Sul, utilizam-se o modelo ECD e, como complemento na tipificação da conduta, as estratégias de Porter (1980) e de Mintzberg (1988).

\subsection{A concentração na indústria de massas alimentícias}

A evolução da concentração na indústria de massas alimentícias do Rio Grande do Sul pode ser vista na Tabela 1 , onde está o grau de concentração $(\mathrm{Cr})$ das quatro maiores empresas em relação ao faturamento e o número de empregados, para os anos de 2002, 2004 e 2006. Os dois indicadores utilizados indicam que a concentração na indústria vem declinando, pois, no ano de 2002, o CR4 em relação ao faturamento foi de 72,31\% e no ano de 2006 caiu para 48,67\%. O mesmo ocorreu com o CR4 em relação ao número de empregados, queda de 67,38\% em 2002 para 45,41\% em 2006.

Revista de Negócios, ISSN 1980-4431, Blumenau, v16, n.3, p.96 - 112, Julho/Setembro 2011. 
Tabela 1 - Razão de concentração para as quatro maiores empresas produtoras de massas alimentícias

\begin{tabular}{ccc}
\hline Ano & $\begin{array}{c}\text { CR4 } \\
\text { Faturamento }\end{array}$ & $\begin{array}{c}\text { CR4 } \\
\text { No Empregados }\end{array}$ \\
\hline 2002 & $72,31 \%$ & $67,38 \%$ \\
2004 & $58,35 \%$ & $55,33 \%$ \\
2006 & $48,67 \%$ & $45,41 \%$ \\
\hline
\end{tabular}

Fonte: Calculados a partir de dados da pesquisa de campo.

A queda da concentração na indústria pode ser explicada, em parte, pela saída de grandes produtores do mercado ou pela redução na produção dos mesmos. Este fato ocorreu na produção de massas alimentícias, pois uma das grandes empresas saiu do mercado (a qual possuía em $2002,27,80 \%$ das vendas) e outra foi vendida e reestruturada, passou de $25,02 \%$ das vendas em 2004 para 7,25\% em 2006.

Tabela 2 - Índice Herfindahl-Hirschman (HH) da indústria de massas alimentícias

\begin{tabular}{cc}
\hline Ano & HH - $\mathrm{N}^{\circ}$ de empregados \\
\hline 2001 & 1666,03 \\
2006 & 849,18 \\
\hline
\end{tabular}

Fonte: Calculados a partir do cadastro industrial da Fiergs dos anos de 2002 e 2007.

O índice HH (ver Tabela 2) também revela que houve uma redução na concentração da indústria entre 2001 e 2006, e isto significa que a concorrência se intensificou no mercado. Além disso, verifica-se que o índice é relativamente baixo em $2006(849,18)$ e está muito distante do nível máximo de concentração (10.000).

\subsection{Barreiras à entrada na indústria de massas alimentícias}

Com os resultados da pesquisa de campo (ver Tabela 3), constata-se que uma das principais barreiras à entrada para a indústria de massas alimentícias é o valor do investimento inicial. Isto pode ser explicado pela necessidade crescente de capital para se produzir em larga escala. Além disso, o investimento exigido é altamente especifico, pois exige maquinário diferenciado, que dificilmente pode ser adaptado para a produção de outro bem que não seja o de massas alimentícias. De qualquer forma, esse tipo de barreira à entrada também é comum em indústrias intensivas em capital.

Tabela 3 - Notas médias atribuídas a barreiras à entrada de firmas na indústria de massas alimentícias

\begin{tabular}{lc}
\hline Barreiras à entrada & $\begin{array}{c}\text { Notas médias } \\
(0-10)\end{array}$ \\
\hline Capacidade de produção das empresas já instaladas & 8,67 \\
Valor do investimento inicial & 8,50 \\
$\begin{array}{l}\text { Dificuldade em colocar o produto no mercado } \\
\text { Exigência de mão-de-obra especializada }\end{array}$ & 8,17 \\
$\begin{array}{l}\text { Conhecimento exigido para produzir (fórmulas e } \\
\text { processos) }\end{array}$ & 5,83 \\
& 5,67 \\
\hline
\end{tabular}


Quantidade mínima de produção

4,67

Dificuldade na obtenção de matéria-prima

3,83

Acesso à tecnologia de produção (máquinas)

3,33

Fonte: Dados da pesquisa de campo.

A capacidade de produção das empresas já instaladas e a dificuldade de colocar o produto no mercado (o acesso aos canais de comercialização), também foram destacadas como barreiras à entrada. A primeira pode ser explicada pela capacidade ociosa das empresas instaladas, o que dificulta a entrada de novos produtores.

As demais barreiras à entrada pesquisadas receberam dos gestores notas médias relativamente baixas, desqualificando-as como barreiras importantes.

\subsection{Diferenciação do produto e diversificação da produção de massas alimentícias}

Atualmente, existem diversos tipos de massas em cada categoria de produção. Por exemplo, dentro da categoria de massas secas existem as massas padre nosso, estrelinha, argolinha, ave-maria, conchinha, espaguete, furadinho, fuzile, talharim, rigatone, ninhos, penne, entre outros.

$\mathrm{Na}$ categoria de massas frescas, podem-se citar as massas para pizza, pastéis e alguns tipos já citados acima, só que não secos. Este tipo de massa requer refrigeração e a sua perecibilidade é alta. A categoria de massas instantâneas tem menor tempo de cozimento e geralmente é a de mais fácil preparo. Logo, as massas secas diferenciam-se das massas frescas devido a este fator, o tempo de cozimento. A distribuição da produção de massas entre as categorias no ano de 2007 pode ser visualizada na Tabela 4.

Tabela 4 - Divisão da produção de massas alimentícias no Rio Grande do Sul em 2007

\begin{tabular}{lc}
\hline Divisão da produção de massas alimentícias & $\%$ \\
\hline Massas alimentícias secas & 65,34 \\
Massas alimentícias frescas & 26,33 \\
Massas preparadas & 8,33 \\
Massas alimentícias instantâneas & 0,00 \\
\hline
\end{tabular}

Fonte: Dados da pesquisa de campo.

Verifica-se na tabela que a principal produção de massas alimentícias é a de massas secas $(65,34 \%)$, seguida da produção de massas frescas $(26,33 \%)$ e que nenhum dos respondentes da pesquisa informou que produzia massas instantâneas, o que deixa os produtores massas do Rio Grande do Sul limitados aos mercados de maior concorrência e de menor expansão. Este fato pode ser explicado pelo investimento que uma linha de produção de massas alimentícias instantâneas requer quando comparado ao investimento em uma linha de produção de massas secas ou frescas, pois o primeiro exige um pré-cozimento do macarrão antes da secagem.

Portanto, os produtores de massas alimentícias podem ofertar produtos de diferentes formatos, diferentes tempos de cozimento e diferentes utilizações. Logo, a diferenciação do produto, entendida como a introdução pela empresa de uma nova mercadoria que tenha a 
característica de ser substituta próxima de outra anteriormente por ela produzida, é considerável na indústria de massas alimentícias.

Com relação à diversificação da produção, que é a introdução de um produto em um mercado no qual a empresa ainda não participava, contata-se também a produção de pratos prontos (lasanha, pizza, etc..), os quais representam $8,33 \%$ do total de produção de massas alimentícias do Rio Grande do Sul. Isso denota que a indústria local está apenas ingressando nestes mercados, mantendo-se ainda presa a produção tradicional.

Também foi evidenciado na pesquisa que $36 \%$ das empresas atuavam na produção de biscoitos em 2007, buscando uma maior diversificação da produção. Este fato pode ser explicado pela utilização na produção da mesma matéria-prima, a farinha de trigo, e por similaridades no processo produtivo.

\subsection{A conduta (estratégias competitivas) na indústria}

Segundo o modelo ECD, deve-se esperar que a estrutura da indústria de massas alimentícias influencie a conduta das empresas e seja influenciada pela mesma. Para avaliar as condutas das empresas (estratégias) na indústria de massas alimentícias do Rio Grande do Sul, utilizam-se como referenciais teóricos o modelo ECD e as estratégias competitivas de Porter (1980) e de Mintzberg (1988).

\subsubsection{Acordos e contratos na indústria de massas alimentícias}

A produção de massas alimentícias depende primordialmente da oferta de farinha de trigo em quantidade e qualidade suficientes. Como no seu processo predomina a mistura de farinha e água, a qualidade do insumo é um dos principais fatores para promover a segmentação do mercado e viabilizar estratégias de diferenciação do produto. Assim, surge a necessidade de farinhas com blends especiais. Para suprir esta demanda, contratos entre as empresas das indústrias de farinha de trigo e de massas alimentícias são realizados, sendo que $50 \%$ dos produtores de massas alimentícias utilizam-se de contratos. Em relação à compra, $36 \%$ dos produtores de massas alimentícias afirmaram que sempre compram dos mesmos fornecedores.

\subsubsection{As estratégias competitivas na indústria de massas alimentícias}

Ao utilizar as tipologias de Porter para análise das estratégias da indústria, verifica-se que a indústria vem utilizando a diferenciação como estratégia mais relevante (ver Tabela 5), seguida da estratégia de produção com o custo mais baixo. Já o enfoque para nichos específicos vem sendo pouco utilizado.

Tabela 5 - Notas médias atribuídas às estratégias dos produtores de massas alimentícias

\begin{tabular}{llc}
\hline & Estratégias adotadas & $\begin{array}{c}\text { Nota média } \\
(1-5)\end{array}$ \\
\hline \multirow{3}{*}{ Porter } & Produtos diferenciados & 4,17 \\
& Produção com o custo mais baixo & 4,00 \\
& Produção para nichos específicos & 2,00 \\
\hline
\end{tabular}

Revista de Negócios, ISSN 1980-4431, Blumenau, v16, n.3, p.96 - 112, Julho/Setembro 2011. 


\begin{tabular}{llc}
\hline & Qualidade do produto & 4,83 \\
& Oferecer algo diferente em relação ao design & 3,17 \\
& Oferecer serviços agregados como produtos complementares, & \\
& maior prazo de pagamento e menor prazo de entrega & 3,17 \\
\multirow{3}{*}{ Mintzberg } & Investimentos em propaganda & 2,83 \\
& Cobrar um preço mais baixo indiferente do custo de produção & 2,00 \\
& Utilizar as mesmas ações das empresas concorrentes & 1,50 \\
\hline
\end{tabular}

Fonte: Dados da pesquisa de campo.

Entre às estratégias competitivas de Mintzberg (1988), verifica-se que as empresas consideraram a qualidade do produto como sendo a principal forma de diferenciação. Além disso, $85,71 \%$ delas consideraram ser esse o seu grande diferencial competitivo e por isso adotam algum sistema de controle de qualidade. Entretanto, entre as quatorze empresas pesquisadas apenas uma destacou possuir certificação (ISO 9001:2000).

A diferenciação por qualidade deve iniciar na triticultura, pois é a partir do trigo que são geradas determinadas matérias-primas especiais. Portanto, existe a possibilidade de incorporar novos produtos e de melhorar a qualidade, ampliando-se as relações ao longo da cadeia de produção, abrindo-se um espaço para uma maior integração entre os produtores de trigo, a indústria de farinha e a indústria de massas alimentícias, o que não ocorre no Rio Grande do Sul.

Como a indústria no Estado é caracterizada por possuir empresas produtoras de massas alimentícias de pequeno e médio porte (nenhuma empresa esta entre as quatro maiores nacionais), explica-se a preocupação estratégica em custos, pois fica difícil a competição com grandes empresas de massas alimentícias que negociam uma maior e melhor quantidade de farinha de trigo, podendo ofertar o seu produto com um custo mais baixo.

O design também foi citado como estratégia de diferenciação pelos produtores, ou seja, oferecer ao mercado um produto com características distintas dos produtos concorrentes. A diferença básica desta estratégia para a de diferenciação por qualidade é que a diferenciação por design busca oferecer algo diferente e não simplesmente ou necessariamente melhor. Esta é uma alternativa para as empresas de menor porte, pois podem ousar em diferentes misturas, sabores, embalagens, adicionando características diferenciadas aos seus produtos.

Também é possível diferenciar o produto sem necessariamente alterar seus atributos intrínsecos, apenas oferecendo algo mais na venda. Em geral, seria a ampliação do nível de serviços agregados (prazo de entrega menor, financiamento à venda, assistência de vendas) ou a oferta de produtos complementares, o que caracteriza uma estratégia de diferenciação por suporte. Segundo os respondentes da pesquisa, este tipo de estratégia tem a mesma relevância do design (média 3,17).

Outra forma de diferenciar um produto dos concorrentes pode ser, simplesmente, cobrar um preço mais baixo, ou seja, a estratégia de diferenciação por preço. Para os produtores de massas alimentícias esta não é uma estratégia representativa, pois, na sua maioria, afirmaram que praticam preços um pouco acima da média $(64,3 \%)$.

A estratégia de diferenciação por imagem de Mintzberg, que é obtida a partir dos gastos com propaganda e promoção dos produtos, não foi considerada relevante pelos produtores. A seguir, analisa-se o desempenho da indústria de massas alimentícias. 


\subsection{O desempenho da indústria de massas alimentícias}

Neste subitem, avalia-se o desempenho da indústria produtora de massas alimentícias do Rio Grande do Sul. Os indicadores de desempenho avaliados foram a lucratividade, os preços médios e a produção. A pesquisa de campo revelou que a lucratividade média dos produtores de massas alimentícias do Rio Grande do Sul caiu no período analisado, e no ano de 2006 a redução atingiu mais de 50\% das empresas.

A queda na lucratividade da indústria pode ser explicada, pelo menos em parte, pelos preços médios de cada segmento da produção (ver Tabela 6), pois a indústria do Rio Grande do Sul se concentra na produção de massas secas, que possuem menor valor agregado.

\section{Tabela 6 - Evolução dos preços médios em R\$ do quilograma de massas alimentícias no} período de 2002 a 2006

\begin{tabular}{lccccc}
\hline Preço médio $(\mathrm{R} \$ / \mathrm{Kg})$ & 2002 & 2003 & 2004 & 2005 & 2006 \\
\hline Massas Instantâneas & 6,90 & 8,57 & 9,12 & 8,33 & 8,62 \\
Massas Frescas & 6,75 & 6,77 & 6,82 & 6,81 & 6,75 \\
Massas Secas & 2,47 & 3,14 & 3,11 & 2,91 & 2,86 \\
\hline
\end{tabular}

Fonte: Abima (2007).

Comparando-se os preços médios das massas secas com os das massas instantâneas e frescas, verifica-se que, no ano de 2006, a diferença de preços do segmento massas instantâneas em relação ao de massas secas chega a mais de $200 \%$ e o de massas frescas em relação ao de massas secas supera os 136\%. Em relação à evolução dos preços, constata-se que as massas secas tiveram o seu maior preço em 2003 e desde então os mesmo caíram 9\%, se comparado ao de 2006. Para as massas frescas, observa-se um comportamento mais estável dos preços e para as massas instantâneas há um incremento de, aproximadamente, $25 \%$ nos níveis de preços praticados de 2006 em relação a 2002.

A maior concorrência no mercado pode ter contribuído para essa piora no desempenho da indústria, uma vez que a produção de massas no Estado aumentou de 167.123 toneladas em 2002 para 183.005 toneladas em 2006 (acréscimo de 9,50\%) e a produção nacional cresceu $14,02 \%$ no mesmo período. Com a menor expansão da indústria gaúcha, caiu a participação de mercado de 15,70\% em 2002 para 15,01\% em 2006. Os índices de concentração reforçam a idéia de aumento da concorrência no mercado, já que houve queda no $\mathrm{Cr} 4$ e no $\mathrm{HH}$ (ver subitem 4.1). Portanto, os indicadores de desempenho utilizados para a indústria, revelam que está ocorrendo uma perda de competitividade da indústria gaúcha.

\section{CONCLUSÕES}

O estudo identifica as estratégias e avalia a organização da indústria de massas alimentícias do Rio Grande do Sul. Constatou-se uma queda nos níveis de concentração da indústria com base nos dois índices utilizados, razão de concentração (Cr4) e HerfindahlHirschman $(\mathrm{HH})$. O Cr4, que determina a participação de mercado das quatro maiores empresas em relação ao faturamento e ao número de empregados passou de 72,31\% em 2002 para 48,67\% em 2006 (com base no faturamento) e de 67,38\% em 2002 para 45,41\% em 2006 
(com base no número de empregados). O índice HH (calculado com base no número de empregados) também teve uma queda expressiva no período, pois era de 1.666,03 em $2001 \mathrm{e}$ passou para 849,18 em 2006.

A queda na concentração indica um aumento da concorrência no setor. Entretanto, foram identificadas algumas barreiras à entrada na indústria que podem limitá-la, como o elevado investimento inicial, a capacidade instalada das empresas e a dificuldade de acesso a canais de comercialização.

A conduta das empresas pode ser justificada pelas características estruturais da indústria. Em relação às estratégias competitivas de Porter, a diferenciação do produto foi a mais destacada pelos gestores das empresas produtoras de massas alimentícias. Entre as tipologias de Mintzberg, a qualidade do produto foi considerada como sendo o diferencial competitivo dos produtores.

Os esforços estratégicos das empresas, como diferenciação e qualidade do produto, não estão sendo suficientes para melhorar o desempenho das empresas, uma vez que a lucratividade está em queda, os preços das massas secas seguem a mesma tendência e perdem participação no mercado.

O estudo proporciona duas contribuições importantes, teórica e gerencial, especialmente para a comunidade acadêmica, os gestores das empresas da indústria de massas alimentícias do Rio Grande do Sul e os representantes de classe dos fabricantes. No campo teórico, o trabalho mostra que a utilização de mais de um referencial teórico na análise amplia a capacidade de entendimento da indústria e permite detectar um maior número de ações. No campo gerencial, a contribuição está relacionada a dois aspectos: dá uma visão geral das ações e resultados dos principais produtores do setor e mostra a debilidade da indústria por falta de estratégias robustas, capazes de influenciar positivamente nos resultados.

\section{REFERÊNCIAS}

ABIMA. Associação brasileira das indústrias de massas alimentícias. Disponível em:<http://www.abima.com.br/est_mnacional.html>. Acesso em: 15 mai. 2007.

ABITRIGO. Associação brasileira das indústrias de trigo. Disponível em: < http://www.abitrigo.com.br/banco_de_dados.asp>. Acesso em: 30 mai. 2007.

BEM, J. S. Estrutura - conduta - desempenho de mercado das indústrias. Análise, Porto Alegre, v. 1, n. 5, p. $523-538,1991$.

CARLTON B.; PERLOFF, J. Modern industrial organization. Harper Collins, 1990.

FARINA, E. M. M. Q. Moinho Pacífico: Ajustamentos e Desafios do Livre Mercado. Anais do III Seminário Internacional de Agribusiness. São Paulo: PENSA/FEA/USP, 1993.

FARINA, E. M. M. Q. Competitividade: mercado, estado e organizações. São Paulo: Singular, 1997.

FIERGS. Federação das indústrias do rio grande do sul. Disponível em: http://www.fiergs.com.br/cadastroindustrial. Acesso em: 28 jun. 2007.

GIL, A. C. Como elaborar projetos de pesquisa. São Paulo: Atlas, 1996.

HILL, C. Differentiation versus low cost or differentiation and low cost: a contingency framework. The Academy of Management Review, v. 13, n.3, p. 401- 412, Jul. 1988. 
KON, A. Economia Industrial. São Paulo: Nobel, 1994.

KOTHA, S.; VADLAMANI, B. L. Assessing generic strategies: an empirical investigation of two competing typologies in discrete manufacturing industries. Strategic Management Journal, v.16, p.75-83, 1995.

LEITE, A. L. Concentração e desempenho competitivo no complexo industrial de papel e celulose 1987-1996. 1998. 99f. Dissertação (Mestrado em Engenharia de Produção) Universidade Federal de Santa Catarina, Florianópolis, 1998.

MORAES, M. A. A indústria de madeira preservada no Brasil: um estudo de sua organização industrial. Piracicaba, 1996. 154p. Dissertação de Mestrado - Escola Superior da Agricultura "Luiz de Queiroz" - ESALQ / USP, Piracicaba, 1996.

MARION FILHO, P. J. A evolução e a organização recente da indústria de móveis nos estados de Santa Catarina e Rio Grande do Sul. 1997. 151f. Tese (Doutorado em Economia Aplicada) - Escola Superior da Agricultura "Luiz de Queiroz" - ESALQ / USP, Piracicaba, 1997.

MILLER, A.; DESS, G. Assessing Porter's (1980) model in terms of its generalizability, accuracy and simplicity. Journal of Management Studies, v. 30, n. 4, p.553 - 585, Jul. 1993.

MINTZBERG, H. Generic Strategies: Toward a Comprehensive Framework, Advances in Strategic Management, v.5 JAI Press Greenwich - CT p.1-67, 1988.

PORTER, M. E. Competitive strategy: techniques for analysing industries and competitors. New York: Free Press, 1980.

PORTER, M. E. Estratégia competitiva. Técnicas para analise de indústrias e concorrência. 7. ed. Rio de Janeiro: Campus, 1986.

ROSA, L. C. Contribuição metodológica para análise estrutural de sistemas agroindustriais: um estudo de segmento produtor de vinhos finos do Rio Grande Sul. 2001.Tese (Doutorado em Engenharia de Produção) - Universidade Federal de Santa Catarina, Florianópolis, 2001.

RESENDE, M.; BOFF, H. Concentração industrial. In: KUPFER, D.; HASENCLEVER, L. Economia industrial: fundamentos teóricos e práticas no Brasil. Rio de Janeiro: Campus, 2002 .

SCHERER, F. M.; ROSS, D. Industrial market structure and economic performance. 3. ed. Chicago: Raud Mc Nally e Co, 1990.

SILVA, J. F.; CARNEIRO, J. M. T.; CAVALCANTI, M. A. D. F. Impactos da privatização sobre as estratégias competitivas de empresas de petróleo: um estudo de caso. RAEeletrônica, v. 2, n. 2, jul./dez. 2003.

SILVA, J. F.; MELO, M. A. C. . Tipologias estratégicas concorrentes: um teste empírico na indústria brasileira de seguros. In: 22 ENANPAD, 1998, Foz do Iguaçu. Anais. Rio de Janeiro: ANPAD, 1998.

USDOJ. United States Department of Justice. The Hirschman - Herfindahl Index, In: Horizontal Merger Guidelines, 1997.

ZAEYEN, A. Estrutura e desempenho do setor de papel e celulose no brasil. 1986. 99f. Dissertação (Mestrado em Economia) - Universidade Federal do Rio de Janeiro, Rio de Janeiro, 1986. 